\title{
Development of Mathematical Skills Like a Support to Executive Functions in Mexican Students and the Psycho-pedagogical Benefits
}

\author{
Dan-el Neil Vila Rosado ${ }^{1}$, Miriam Minerva Garcia Durán ${ }^{2}$, Jose Luis Rodriguez Riera ${ }^{3}$ \\ ${ }^{1}$ Mathematical Center Campeche, Campeche, Mexico,dnvr30@cimat.mx \\ ${ }^{2}$ Mathematical Center Campeche, Campeche, Mexico,miriamine22@hotmail.com \\ ${ }^{3}$ Mathematical Center Campeche, Campeche, Mexico,jlrr1996@hotmail.com
}

\begin{abstract}
The development of our skills in any area is important to overcome difficulties and to grow both personally and professionally. The executive functions are the main tools of an individual to achieve goals or for adaptation to several contexts of development, particularly in education. Mexican education is not at its best, evaluation programs such as the National Assessment of Academic Achievement in Schools (ENLACE), Quality Exams and Educational Achievement (EXCALE) and PISA (Program for International Student Assessment) proves that Mexican infants have a deficit in the learning of basic skills such as mathematics and reading comprehension. Theoretically, the Mexican education is focused on the development of the executive functions, but in practice the educational models implemented does not have an effective strategy. The Mathematical Center Campeche is aware of the situation and proposes as a first step the development of basic mathematical skills at a level before the executive functions. We developed educational material to support children to suppress inappropriate responses that interfere with the achievement of a goal (inhibitory control) and respond to several tasks simultaneously or plenty objectives of a single task (divided attention). This activity was carried using slideshows and working in sessions between 10 and 15 minutes long. The present paper shows our proposal to improve mathematical skills and their results like the remarkable improvement that learners and teachers had while the investigation was taking place, not only on the activity but on the development of different behaviors.
\end{abstract}

KEYWORDS: divided attention, executive functions, mathematical skills, response inhibition

\section{Introduction}

Evaluation programs such as the National Assessment of Academic Achievement in Schools (ENLACE), Quality Exams and Educational Achievement (EXCALE) and Programs for International Student Assessment (PISA) show that Mexican education has a clear deficit in the development of basic skills such as mathematics and reading comprehension.

In the PISA 2015 results, it is shown that Mexico is below the average in the reading skill and mathematics skill (OECD 2015). Coupled with it the PLANEA evaluation shows that the $73.9 \%$ of Mexican children in third grade of secondary education are at a basic or insufficient level of language and communication skill and an $86.2 \%$ are at a basic or insufficient level in mathematics (INEE 2018). The case of the state of Campeche, Mexico is more worrisome. An example of this is that in the ENLACE-2012 44\% of primary students and $76 \%$ of secondary students are in the insufficient and elementary level (SEP 2013). Even more, recently the PLANEA 2017 evaluation shows that 71.7\% of children in third grade of secondary in Campeche are in a basic or insufficient level of language and communication and an $86.9 \%$ are in a basic of insufficient level in mathematics (INEE 2018).

In the theoretical considerations of the Mexican educational system in the "Program of Study 2011" (Secretaría de Educación Pública 2012) in the section of "Purposes of the study of Mathematics in basic education" is pointed out that children and adolescents should:

- Develop ways of thinking that allows them to formulate conjectures and procedures to solve problems, as well as to elaborate explanations for certain numerical or geometric facts.

- Use different techniques or resources to make more efficient procedures.

- Show disposal for the study of mathematics, as well as autonomous and collaborative work.

Besides, the "Curriculum Standards for Mathematics in the 2011 Mexican Program" indicates what is expected of the students at the basic level of education and is organized as follows:

- Number Sense and Algebraic thinking. 
- Form, Space and Measure; Information Management.

- Attitude towards the study of Mathematics.

In addition to it, the new educational reform that would be implemented in 2018 contemplate the development of different skills including reading comprehension and various mathematical skills to teach children and adolescents to be autodidact (Nuño et al. 2017). Nevertheless, in the present, the teaching of mathematics in Campeche is more focused on the learning of the mathematical knowledge than on the development of mathematical skills. Due to this, it has increased the need for create support strategies that allows students and teachers to get better at the teaching-learning process, especially in the areas of mathematics and reading comprehension. The Mathematical Center Campeche (CMC) is aware of the situation, so that the first approach is intended to support students to foster their mathematical skills focusing on the development of the basic cognitive processes for better learning.

Owing to the above, in the present paper the study and development of tools for the basic cognitive processes to improve learning is presented. We focused in the inhibitory control due to the importance of having a restraint of the automatic and impulsive responses to replace them with responses mediated by attention and reasoning (Rubiales 2013,50) as well in the divided attention which allows us to respond to several task or plenty objectives of a task simultaneously (Brailowski $1995,49)$. The main goal of this work is to teach teachers to motivate and develop mathematical skills in their students by showing some of the benefits that this practice could offer.

In this paper, we give a general explanation of what mathematical skills are so then to emphasize the two main skills of this investigation: Response Inhibition and Divided Attention. Next the case study will be presented talking about our study objects, condition, context, etc. Then the methodology will be explained: what methods we use and how do use them. Eventually the results will be presented using graphics that shows the process of advancing of the students during the investigation. Finally, the conclusions will be presented.

\section{Mathematical Skills}

\section{General description}

Mathematical skills could be defined as the student's construction of the inherent way of acting in a given mathematical activity, which allows him or her to search for or use concepts, properties, relationships, mathematical procedures, work strategies, reasoning, judgements that are necessary for solving mathematical problems (Vicente 2000, 49).

We consider that mathematical skills are a level before executive functions (Bull and Scerif 2001), which are consider as a set of cognitive skills that allows individuals to establish objectives, plan, initiate activities, self-regulate behavior, monitor tasks, select behaviors and perform actions to achieve objectives (Diamond 2013, 64). We identified thirteen basic mathematical skills organized as exhibited in Figure 1. However, at this paper, we will focus on the skills of response inhibition and divided attention. 


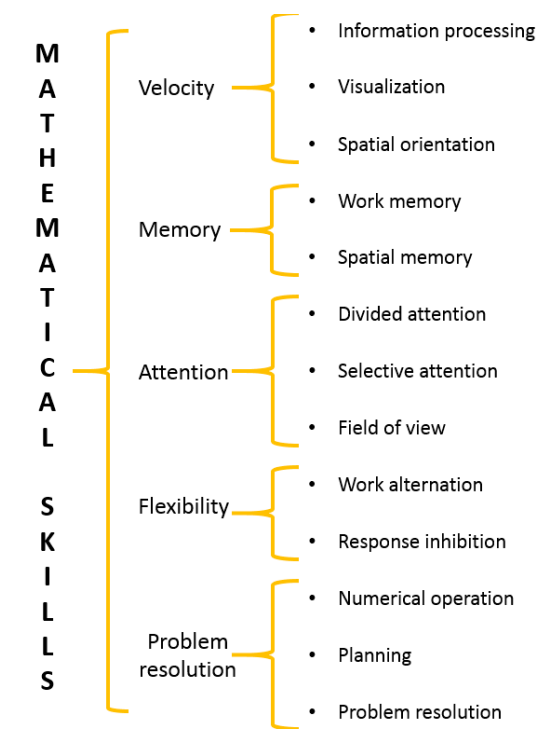

Figure 1. Mathematical skills organization

\section{Response Inhibition}

The inhibition is the annulment of automated, predominant or guided by rewards responses, which are inappropriate for the current demand (Bechara 2010, 227).

The mental processes of inhibition refer to those mental processes in charge of the intentional and voluntary control, as well as the ability to prevent the interference of non-relevant information to ongoing responses and suppress previously relevant information that may bring some incentive in the short term but are not useful for the task to be carried out at present (Papazia 2006).

Based on an integral taxonomy for conception of the inhibitory processes, these can be classified into three fundamental classes, which are (Sabbagh 2008, 215):

- Motivational inhibitions: these processes refer to motivated inhibition, be it by behavior or thought.

- Automatic inhibitions: it is relevant in the operation of attention. From the point of view of the measurement, one could distinguish between an attentional and oculomotor inhibition, which they provide the automatic complement to the inhibition cognitive and motor voluntary, respectively.

- Executive inhibitions: refers to the deliberate suppression of immediate motor behavior, serving a distal goal in the working memory.

With all the above, we can say that Response Inhibition is the ability to inhibit or control automatic or impulsive responses to give rise to responses mediated by attention and reasoning. The inhibition of interference can be at motor, behavioral or attentional level.

\section{Divided Attention}

The attention is the selective concentration of mental activity that implies an increase in efficiency over a given sector and the inhibition of some current activities. To put attention means focus on something important and ignore the irrelevant (Merani 1979).

Attention has - as its essential property -, to focus and select some important element of the medium, to interact with it. Characteristics are (Arbieto 2002):

- Concentration: is the inhibition of irrelevant information and focus on the important, it implies a focus for long periods and is manifested by its intensity and the resistance to divert attention to other objects or secondary stimuli.

- Distribution of attention: means parallel attention to various objects at the same time, the more linked the objects are to each other, and greater the automation or practice, the more easily distributed the attention. 
- Stability of attention: it refers to keeping the attention on some specific object or activity for a long period of time. It depends on conditions such as: degree of difficulty of the activity, peculiarity and familiarity with it, degree of comprehension and attitude and strength of interest of the person regarding the activity.

- Oscillation of attention: they are involuntary periods of seconds to which attention is subject. The attention oscillates due to us attending two or more information sources or because we perform two tasks and the attention alternates from one to other (shifting).

There exist two different degrees of control of attention, which are (Arbieto 2002):

- Involuntary attention: is related to the appearance of a new stimulus, strong and significant, and disappears almost immediately with the emergence of repetition or monotony.

- Voluntary attention: it develops in childhood with the acquisition of language and school demands, from involuntary attention.

As we can see, there are many different types of attentions, but the one that we are interested in is one related to the distribution of attention combined with the voluntary attention. This means that we will have the ability to respond to several tasks simultaneously or plenty objectives of a single task. This could be the base of the Divided Attention.

\section{Study Case}

The research in charge of the CMC was carried out with children enrolled in the kindergarten "Gabriela Mistral". In total we worked with 85 children divided into four groups as follows: 19 children of the 1st grade group (14 girls and 5 boys), 26 children of the 2 nd grade group (15 girls and 11 boys), 19 children in the 3rd grade group A ( 8 girls and 11 boys) and 21 children in the 3rd grade group B (12 girls and 9 boys).

\section{Methodology}

The ability of Response Inhibition was worked once a week in sessions of 15 minutes as maximum. This exercise contains two levels of difficulty differentiated by the number of possible answers, having three for level one and four for level two. In this skill, there is a time of eight seconds per problem. Several cards at the top of the screen and one on the bottom are presented, the card below must be accommodated in one of the top cards depending on the slogan found in the lower right corner. There are three types of slogans:

- Star: the card must be accommodated by the shape of the figures it contains.

- Hash: the card must be accommodated by the number of figures in it.

- Full purple square: the card must be accommodated by the color of the figures.

Children choose their answer either by saying it or by writing the number, which it corresponds. For the Divided Attention skill, we worked twice a week with duration of ten to fifteen minutes. The exercise contains two difficulty levels differentiated by the number of figures that must be paid attention, two for level one and three for level two. This skill is presented in five seconds per problem. In this exercise, the figures are presented and attention must be paid to all and to see which changes. Children choose their answer by saying which one changes.

Due to the complexity of the Inhibitory Control exercise, it was decided to work that skill with $2^{\text {nd }}$ and $3^{\text {rd }}$ grade and leave the Divided Attention exercise for the $1^{\text {st }}$ grade.

\section{Results}

The images below presents the data obtain from the students as it follows: $2^{\text {nd }}$ grade Response Inhibition (Figure 2), $3^{\text {rd }}$ grade A Response Inhibition (Figure 3), $3^{\text {rd }}$ grade B Response Inhibition (Figure 4) and $1^{\text {st }}$ grade Divided Attention (Figure 5). 


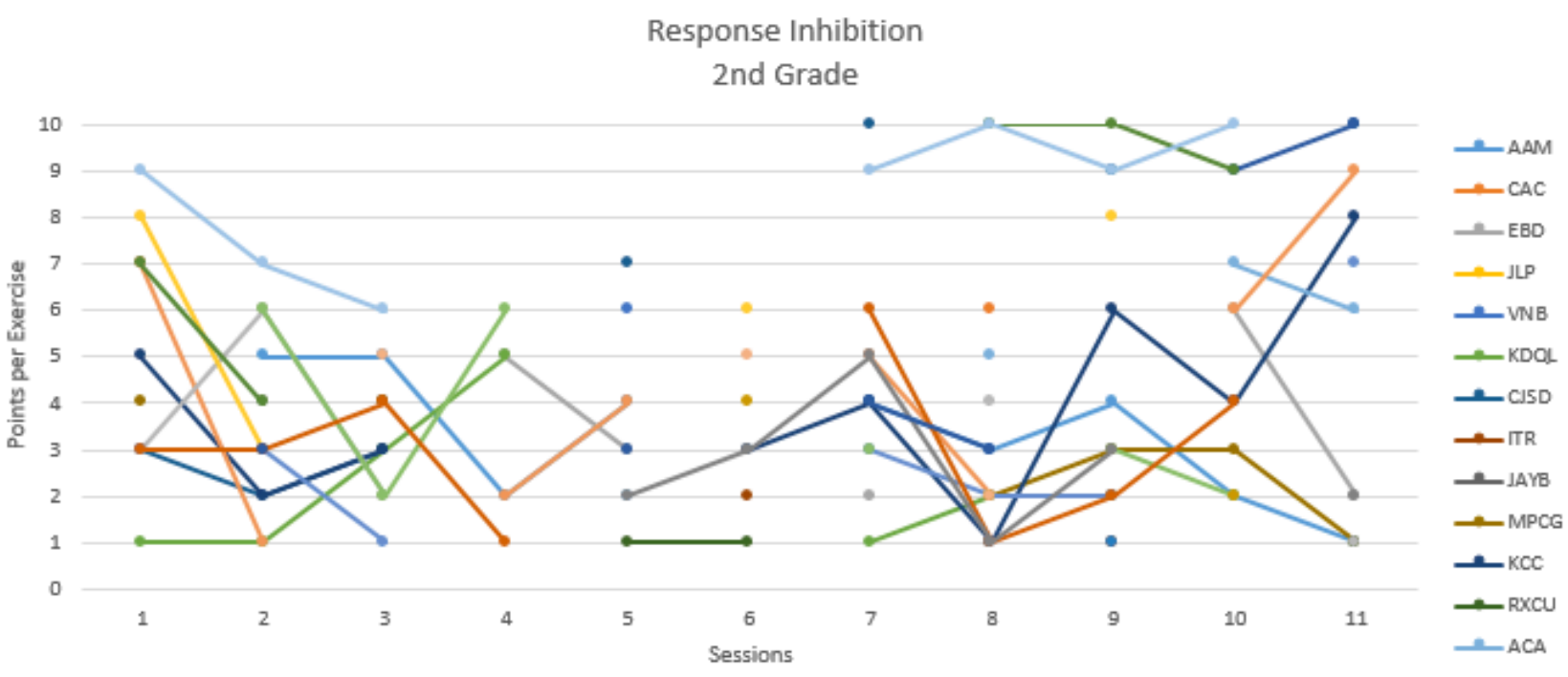

Figure 2. $2^{\text {nd }}$ Grade Response Inhibition

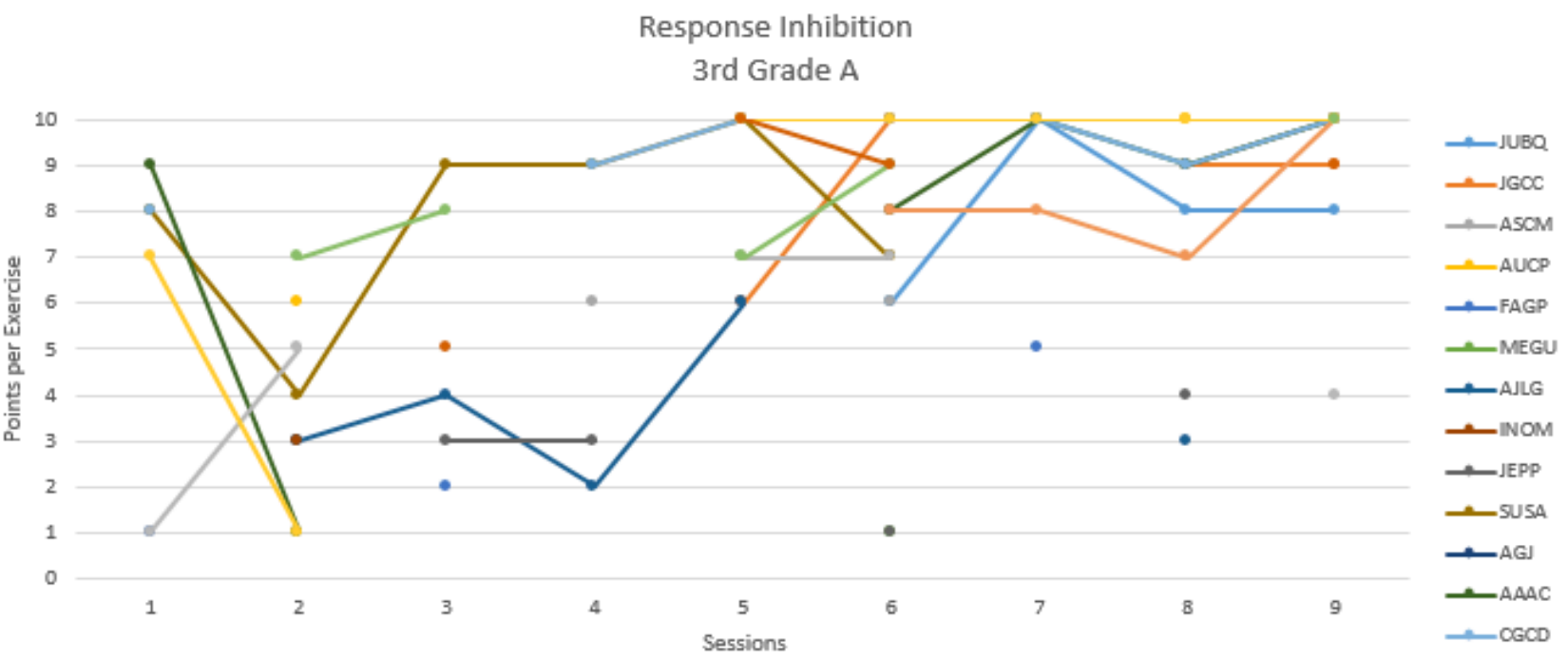

Figure 3. $3^{\text {rd }}$ Grade, Response Inhibition Response Inhibition 3rd Grade B

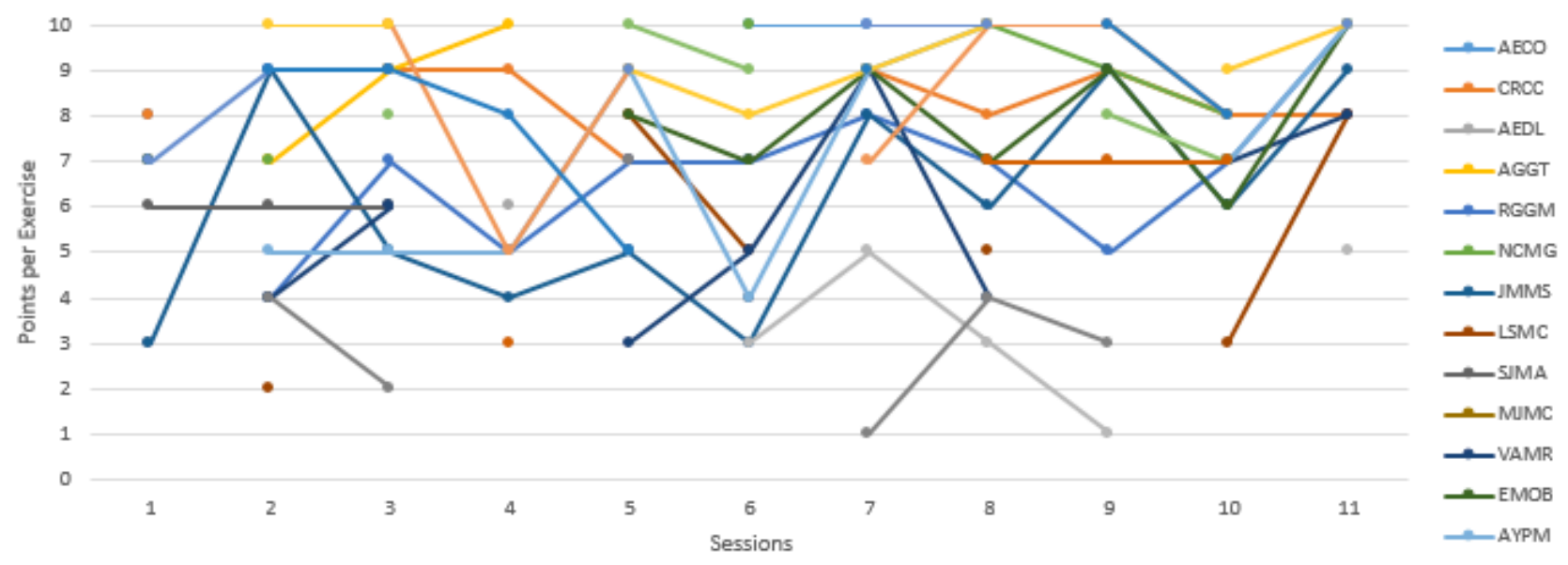

Figure 4. $3^{\text {rd }}$ Grade, Response Inhibition 


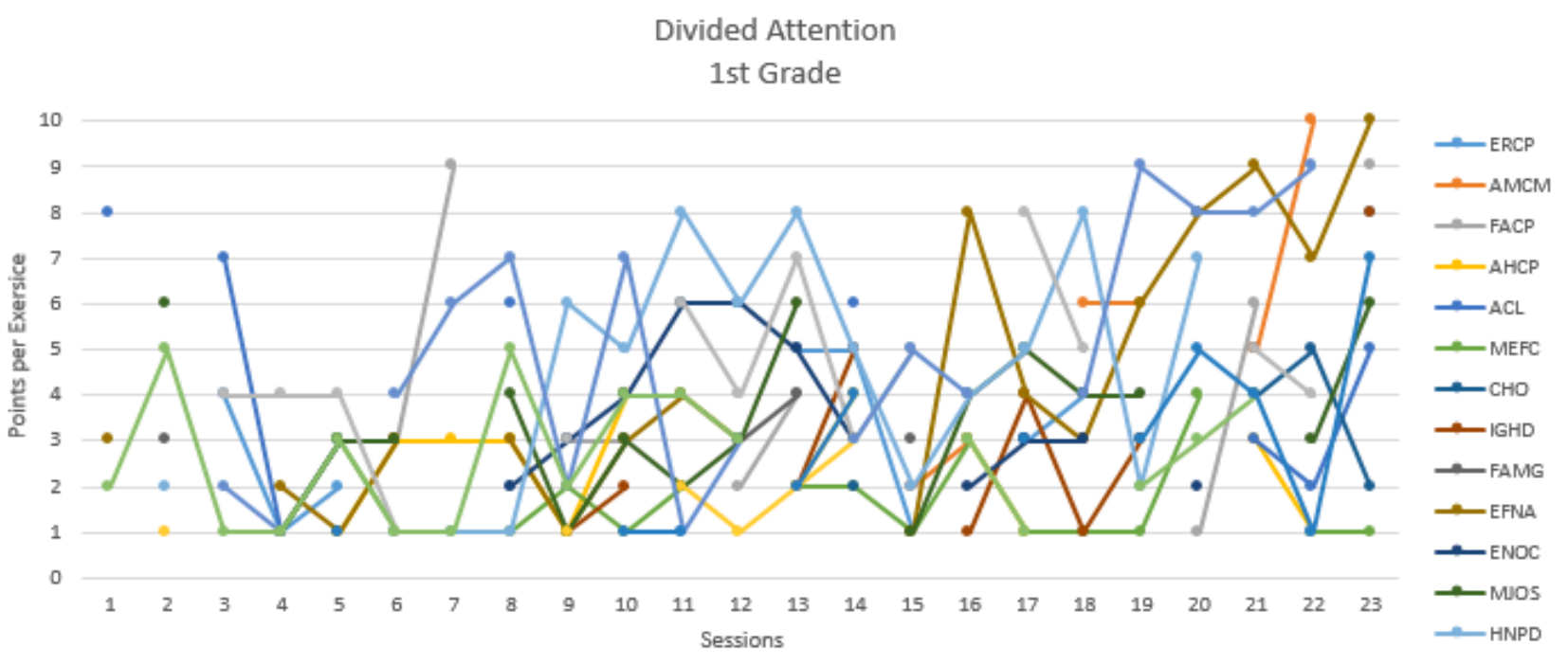

Figure 5. $1^{\text {st }}$ Grade, Divided Attention

\section{Conclusions}

The fact of applying the tools in children to improve the mathematical skills of Response Inhibition has resulted, in addition to the improvement in said skill, the development of their ability to remain focused on a task despite having external stimuli that may interfere in the performance of it. This was observed specially during the last sessions of application, due to while some children performed the exercise of the mathematical skill others rehearsed for the closing of the school year festival, and although many children were called by music, they were aware of what they should do.

Regarding the Divided Attention skill, it was observed that the students were able to improve their ability to respond various things at once, either by carrying out the current task while giving a new instruction or, in some cases during their music class, improving his ability to follow the rhythm of a song with palms while they sang.

These improvements became more noticeable as soon as the skill exercises and other activities were put into practice, especially when comparing the children who were constant in the exercises with respect to those who - for some reason - could not be.

Something noteworthy is the drop in their abilities to perform both the exercises and maintaining these improvements after a long period of not practicing them, either for holidays or for not being able to attend class either for health problems or other.

Finally we could observe that the more constant they were with the practice of their mathematical skills, the children will be able to face with greater ease exercises of a higher level of difficulty advancing to the next one or decreasing the solving time.

\section{Acknowledgments}

We must mention that the success of this project for the development of mathematical skills in students of Campeche has been able thanks to the trust and support of the "Gabriela Mistral" kindergarten principal B. Elda Esther Castillo Quintana and her work group. Thanks for the unconditional support!

\section{References}

Arbieto, K. 2002. "The attention." Psychopedagogy. Recovered on January 28, 2017, from http://www.psicopedagogia.com/atencion.

Bechara, A. V-G. 2010. "Neuropsychology of executive functions." Psicothema 22(2): 227-235.

Brailowsky, S. M. 1995. Selective Attention II: Electrophysiological mechanisms and alterations. Mental health 4: 49-54.

Bull, R., and G. Scerif. 2001. "Executive Functioning as a Predictor of Children's Mathematics Ability: Inhibition, Switching, and Working Memory." Developmental Neuropsychology $19 \quad$ (3): 273-293, DOI: 10.1207/S15326942DN1903_3. 
Diamond, A. 2013. "Executive functions.” Annual review of psychology 64:135-168.

INEE. 2018. "PLANEA National Results 2017". México.

Merani, A. L. 1979. Psychology dictionary (Spanish Edition). México: Grijalbo.

Nuño, A., O. Granados, S. Jara, R. Tuirán, J. Treviño, and A. Gómez. 2017. Educational model for compulsory education. Mexico City, Mexico: SEP.

OECD. 2015. "PISA 2015 Results in Focus". PISA, OECD Publishing, Paris, https://www.oecd.org/pisa/pisa-2015results-in-focus.pdf.

Papazia, O., and I. Alfonso. 2006. "Executive function disorders.” Rev Neurol 42(Suppl 3): S45-50.

Rubiales, J. L. B. 2013. "Comparative study of inhibitory control and cognitive flexibility." Neuropsychology Notebooks 50-54.

Sabbagh, S. S. 2008. "Written arithmetic problems solving and cognitive inhibitory control." Universitas Psycologica 7(1): 215-228.

SEP. 2013, "ENLACE 2013. Historical results 2006-2013. Campeche.” Mexico: SEP.

Secretaría de Educación Pública. 2012. "Study program 2011. Guide for the teacher”. México, D.F.: Basic Education.

Vicente, M. F. 2000. "The resolution of problems in the structure of a system of mathematical skills in Cuban middle school." PhD diss., pp. 49-51. Santiago Cuba. 